\title{
Terrestrial animal tracking as an eye on life and planet
}

Roland Kays, ${ }^{*}$ Margaret C. Crofoot, Walter Jetz, Martin Wikelski
BACKGROUND: The movement of animals makes them fascinating but difficult study subjects. Animal movements underpin many biological phenomena, and understanding them is critical for applications in conservation, health, and food. Traditional approaches to animal tracking used field biologists wielding antennas to record a few dozen locations per animal, revealing only the most general patterns of animal space use. The advent of satellite tracking automated this process, but initially was limited to larger animals and increased the resolution of trajectories to only a few hundred locations per animal. The last few years have shown exponential improvement in tracking technology, leading to smaller tracking de- vices that can return millions of movement steps for ever-smaller animals. Finally, we have a tool that returns high-resolution data that reveal the detailed facets of animal movement and its many implications for biodiversity, animal ecology, behavior, and ecosystem function.

ADVANCES: Improved technology has brought animal tracking into the realm of big data, not only through high-resolution movement trajectories, but also through the addition of other on-animal sensors and the integration of remote sensing data about the environment through which these animals are moving. These new data are opening up a breadth of new scientific questions about ecology, evolution,

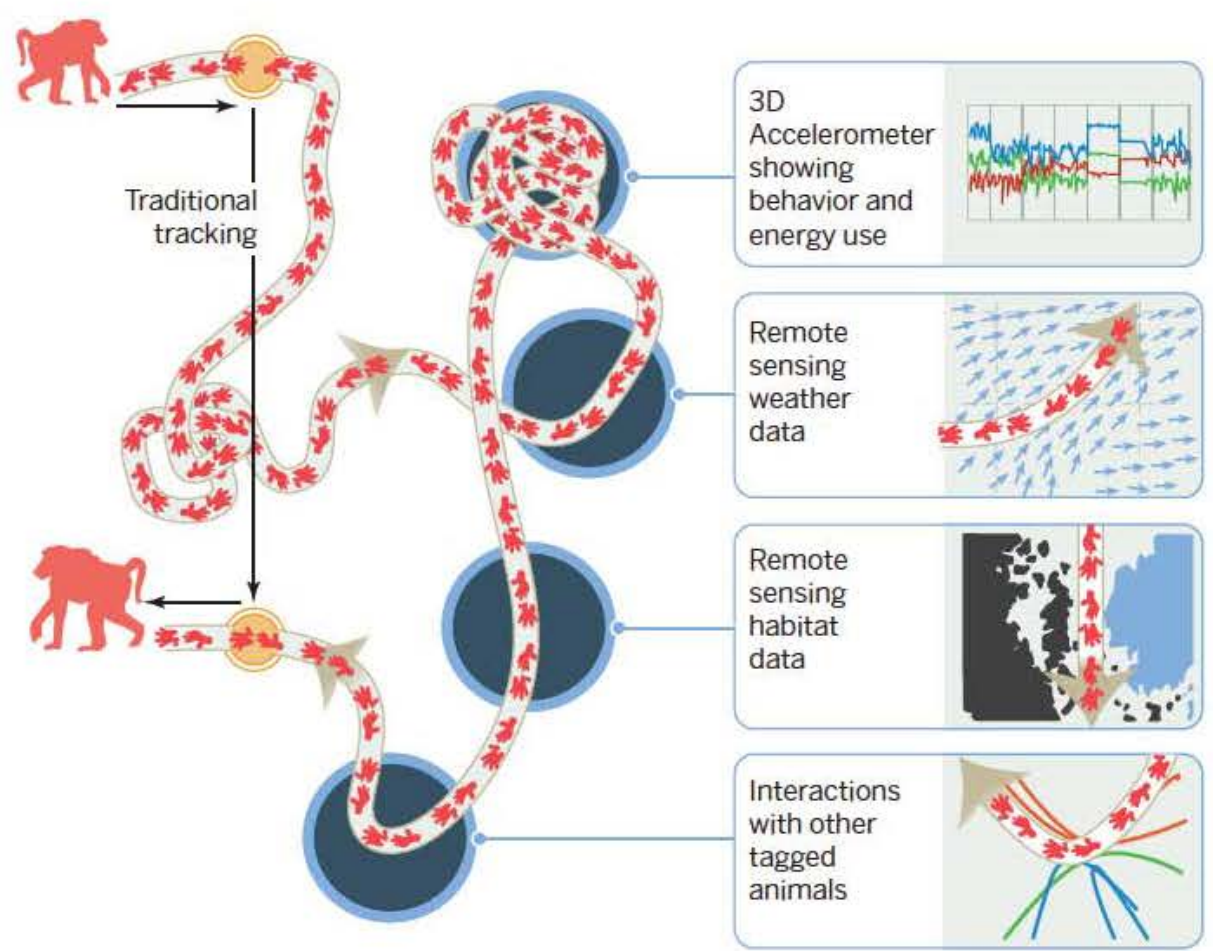

Big-data animal tracking. The red trajectory shows how studies can now track animals with unprecedented detail, allowing researchers to predict the causes and consequences of movements, and animals to become environmental sensors. Multisensor tracking tags monitor movement, behavior, physiology, and environmental context. Geo- and biosciences merge now using a multitude of remote-sensing data. Understanding how social and interspecific interactions affect movement is the next big frontier. and physiology and enable the use of animals as sensors of the environment. High temporal resolution movement data also can document brief but important contacts between animals, creating new opportunities to study social networks, as well as interspecific interactions such as competition and predation. With solar panels keeping batteries charged, "lifetime" tracks can nowbe collected for some species, while broader approaches are aiming for species-wide sampling across multiple populations. Miniaturized tags also help reduce the impact of the devices on the study subjects, improving animal welfare and scientific results. As in other disciplines, the explosion of data volume and variety has created new challenges and opportunities for information management, integration, and analysis. In an exciting interdisciplinary push, biologists, statisticians, and computer scientists have begun to develop new tools that are already leading to new insights and scientific breakthroughs.

OUTLOOK: We suggest that a golden age of animal tracking science has begun and that the upcoming years will be a time of unprecedented exciting discoveries. Technology continues to improve our ability to track animals, with the promise of smaller tags collecting more data, less invasively, on a greater variety of animals. The big-data tracking studies that are just now being pioneered will become commonplace. If analytical developments can keep pace, the field will be able to develop realtime predictive models that integrate habitat preferences, movement abilities, sensory capacities, and animal memories into movement forecasts. The unique perspective offered by big-data animal tracking enables a new view of animals as naturally evolved sensors of environment, which we think has the potential to help us monitor the planet in completely new ways. A massive multi-individual monitoring program would allow a quorum sensing of our planet, using a variety of species to tap into the diversity of senses that have evolved across animal groups, providing new insight on our world through the sixth sense of the global animal collective. We expect that the field will soon reach a transformational point where these studies do more than inform us about particular species of animals, but allow the animals to teach us about the world.

\section{RELATED ITEMS IN SCIENCE}

N. E. Hussey et al., Science 348, 1255642 (2015).

*Corresponding author. E mail: roland.kays@ncsued. 


\title{
Terrestrial animal tracking as an eye on life and planet
}

\author{
Roland Kays, ${ }^{1,2,3 *}$ Margaret C. Crofoot, ${ }^{3,4,5}$ Walter Jetz, ${ }^{6,7}$ Martin Wikelski ${ }^{3,5,8}$
}

Moving animals connect our world, spreading pollen, seeds, nutrients, and parasites as they go about the their daily lives. Recent integration of high-resolution Global Positioning System and other sensors into miniaturized tracking tags has dramatically improved our ability to describe animal movement. This has created opportunities and challenges that parallel big data transformations in other fields and has rapidly advanced animal ecology and physiology. New analytical approaches, combined with remotely sensed or modeled environmental information, have opened up a host of new questions on the causes of movement and its consequences for individuals, populations, and ecosystems. Simultaneous tracking of multiple animals is leading to new insights on species interactions and, scaled up, may enable distributed monitoring of both animals and our changing environment.

M

ovement is a defining characteristic of animals. Animals move to find critical resources such as food and mates and to avoid risk factors such as predators, and their movements are shaped by both evolutionary and ecological processes $(1)$. Move ment rates and patterns determine abundance and diversity at a given point in time and space, as animals enter and leave a location with speeds that range from as slow as a slug to as fast as a peregrine falcon. Moving animals disperse pol len, seeds, and diseases, and determine the spa tiotemporal distribution of herbivory, predation, and many other vital ecological processes, which are valued at many hundreds of billions of dollars per year (2). Animal movement thus provides essential insights into patterns of biodiversity, ecological characteristics of individual species, and ecosystem function.

Despite its long history, the study of animal movement has generally fallen toward the mar gins of ecological research because the data gath ered from wild individuals were too sparse to accurately describe these phenomena. Recent generations of tracking devices have removed these constraints, and it is now possible to record the movements of animals nearly continuously through the use of monitors equipped with Global
Positioning System (GPS) devices (generally referred to as "tags"). This increased temporal resolution has led to important insights about how and why animals move and offers great potential for future discoveries. The addition of secondary sensors to tags complements the move ment data with accelerometry, physiological, or environmental information, providing an inte grated view of the animal and its environment.

New technology has brought the study of an imal movement into the realm of big data (3), and exponential increases in data volumes are expected to continue in the coming decade. For example, a recent 1 month study of the individ uals in a baboon troop collected 20 million GPS locations (at $1 \mathrm{~Hz}$ ) and $\sim 700$ million accelerometry records (4). In some ways, increased temporal resolution of movement patterns is analogous to the genetic insight provided by DNA sequencers: Animal steps are our base pairs, movement seg ments are our genes, and combined tracks over an animal's lifetime are analogous to a full ge nome ( 1 ). Data describing the entire lifetime of movement by individual animals, and species wide sampling from multiple populations, are now becoming available (Fig. 1). As in the case of genetics, this avalanche of new data provides the raw material for new insight, but challenges

${ }^{1}$ North Carolina Museum of Natural Sciences, Raleigh, NC, USA. ${ }^{2}$ Department of Forestry and Environmental Resources, North Carolina State University, Raleigh, NC, USA.

${ }^{3}$ Smithsonian Tropical Research Institute, Balboa, Republic of Panama. ${ }^{4}$ Department of Anthropology, University of California, Davis, Davis, CA, USA. ${ }^{5}$ Department of Migration and Immuno Ecology. Max Planck Institute for Ornithology, Radolfzell, Germany. ${ }^{6}$ Department of Ecology and Evolutionary Biology, Yale University, New Haven, CT 06520 USA. 'Department of Life Sciences, Imperial College London, Silwood Park Campus, Ascot SL5 7PY, UK ${ }^{8}$ Department of Biology, University of Konstanz, Konstanz, Germany.

*Corresponding author. E mail: roland.kays@ncsu.edu
A

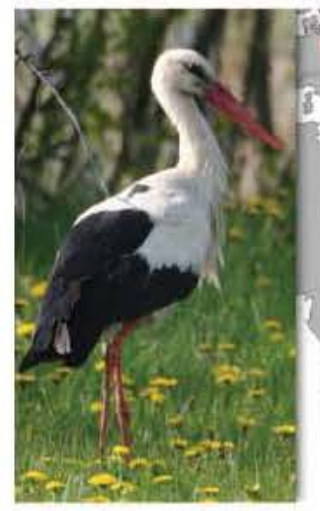

B
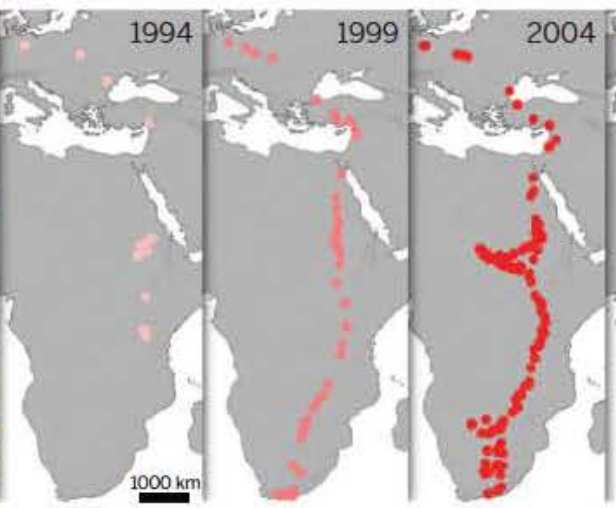

Fig. 1. Lifetime tracks. "Life-tracks" are made possible by solar-powered GPS tags with long life spans, or animals that can be located in real time and recaptured. These maps show detailed tracking data for one individual over its life. "Princess" the white stork (A) (Ciconia ciconia) was tagged with a GPS tracking device as a 3-year-old, nonreproductive juvenile in Germany in 1994 and was tracked until her death in 2006 (B). Four generations of Argos satellite tags were used to track her, and she had to be recaptured and retagged multiple times. Batteries on today's solar-

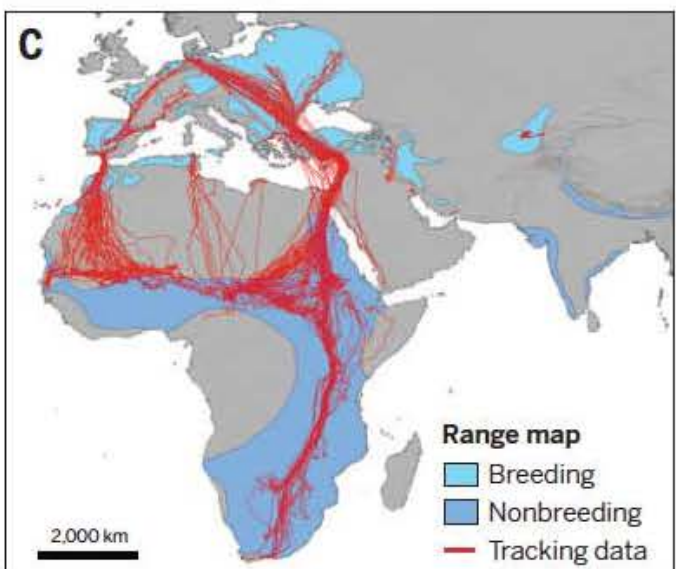

powered tags last much longer. More recent tracking efforts now document the migratory behavior of 11 different populations of storks across their range (C), discovering, e.g., unexpected stationary populations in Uzbekistan and new migratory behaviors in Tunisian storks, which cross the Sahara multiple times per year. Because the GPS data collected by these tags can be accessed anywhere in the world, researchers can also document the cause of death for all juvenile storks, as long as they stay in the range of cell phone networks. [Data from (114)] 
of data management and analysis must first be overcome.

The future of animal tracking will see smaller tags collecting more data, less invasively, on a greater variety of animals. In addition to GPS tags, these could include a series of intercon nected sensors to understand internal physiolog ical state and decision making (5), similar to the body area sensor networks currently being pio neered in human subjects (6). Finally, we expect select cases of massive multi animal tracking to reveal the details of interactions among and within species and also offer distributed moni toring of our changing environment.

\section{Tracking technology: Advances in GPS and sensor technology}

Although scientists have been using electronic tags to track animal movement since the 1960 s (7), data from these early studies were sparse because of the manual labor needed to find and record animal locations. The first automated track ing tags worked with the Argos satellite network but were expensive and relatively inaccurate (8). Since the U.S. Department of Defense stopped its policy of degrading the accuracy of civilian GPS receivers in 2000 , however, the field of animal tracking has exploded. Large scale consumer electronics demand has driven the development of smaller batteries and cheaper, more energy efficient microprocessors, allowing GPS tracking to be an option for most medium or large sized vertebrates (Fig. 2). In the last few years, tracking technology has passed important thresholds in both size and temporal resolution of data collec tion (Fig. 3) and is revolutionizing our under standing of animal ecology.

Locating animals remains the primary objec tive of most animal tracking studies, although tracking tags now typically incorporate a variety of other sensors to help monitor the animal and its environment. Three axis accelerometers built into tags can be used to continuously describe be havior and energy use over an animal's entire lifetime $(9)$ by measuring fine scale body move ments. Implanted electronics can record heart rate, electroencephalographic (EEG) activity, inter nal temperature, and other physiological param eters $(10,11)$. Animal mounted cameras are also now small enough to be useful on terrestrial mam mals and birds, adding new perspective and in sight to the motivations of animal movement (12).

\section{Data in real time}

Real time acquisition of data on the movement and behavior of tagged animals is fundamentally changing the ways that scientists, managers, and conservation groups use animal tracking infor mation. Recovering data from animal borne sen sors has been one of the enduring challenges of bio logging: Until recently, study animals had to be recaptured to access the data stored in their tag's onboard memory. This led to high rates of data loss; for example, $11 \%$ of store on board GPS tags used in one set of mammal tracking studies were never recovered (13), and this sta tistic is presumably worse for migratory birds.
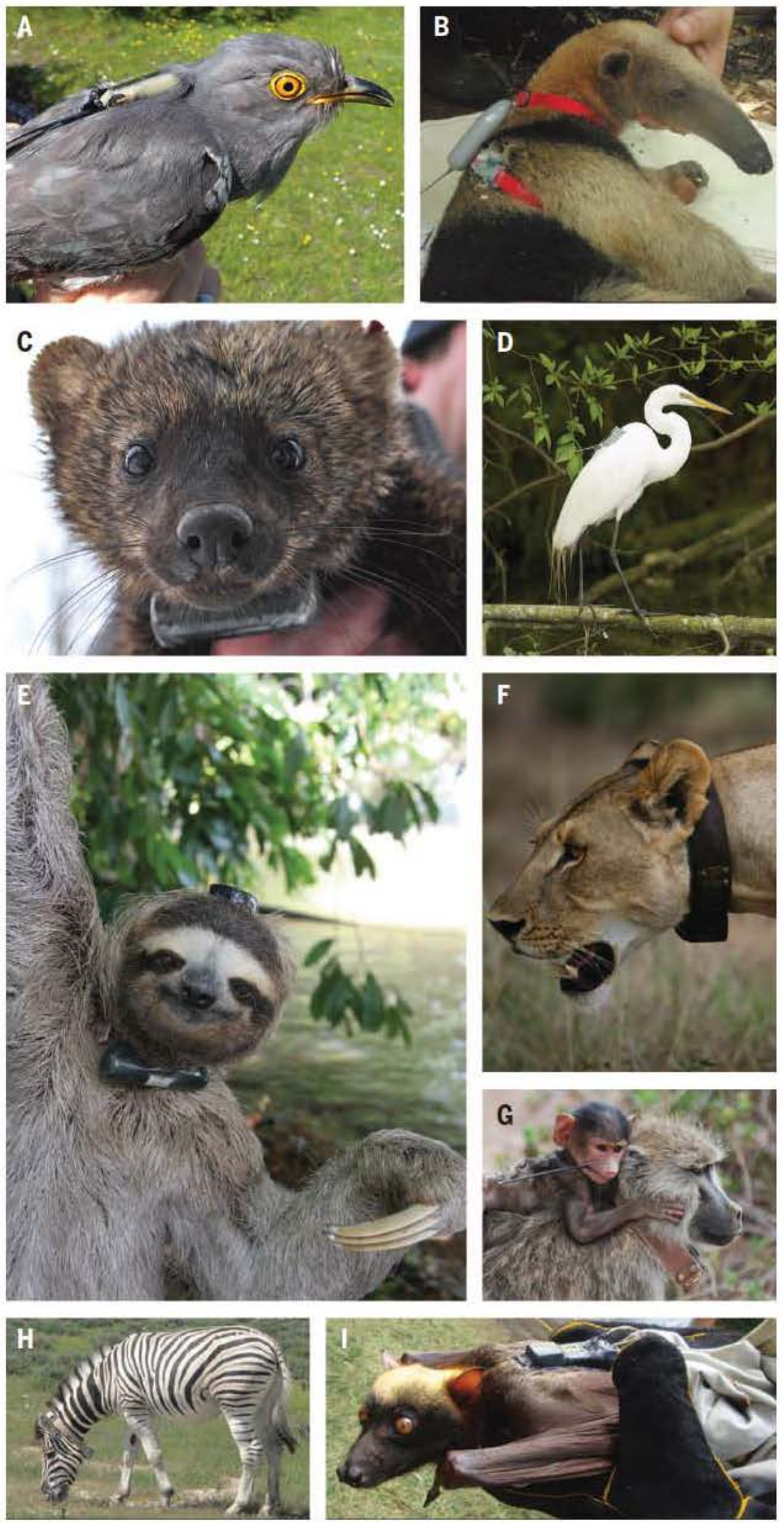

Fig. 2. Tagging animals with technology. Diverse species require diverse tracking technology and attachment methods, including harnesses, collars, and EEG monitors: (A) common cuckoo (Cuculus canorus). (B) northern tamandua (Tamandua mexicana). (C) fisher (Pekania pennanti). (D) great egret (Ardea alba). (E) three-toed sloth (Bradypus variegatus) with a collar and EEG monitor (F), lion (Panthera leo), (G) olive baboon (Papio anubis), (H) plains zebra (Equus quagga), and (I) Lyle's flying fox (Pteropus lylei). 
Furthermore, data logging technology also meant that GPS tracking studies have necessarily been retrospective.

By taking advantage of existing satellite or cell phone communication networks for remote data download, the current generation of tracking tags allow users to move beyond post hoc analyses of where animals moved and to respond immedi ately and interactively to changes in their behav ior. This is akin to the value of historic weather records versus real time weather radar data to mountaineers, pilots, or farmers. Wildlife man agers, for example, are using GPS tags that send SMS alerts when tagged elephants cross into pre defined areas to reduce human wildlife conflict. These "virtual fences" warn people via text mes sage when specific problem animals are nearby and can help managers and landowners reduce crop raids (14). Geofencing also allows automated changes directly to a tag's GPS data collection protocols to adjust sampling frequency at places or times of particular interest, such as initiation of dispersal or migration. Furthermore, live data allow field biologists to immediately backtrack an animal's path and collect additional data, in cluding locating predator kill sites or following snow tracks to identify highway underpass use (15). Live data from tagged animals can also pro vide a powerful tool to engage public interest, involve citizen scientists, and obtain additional data from the field (e.g., Animal Tracker and Glob al Shark Tracker smartphone applications).

\section{Shrinking tag size}

One of the most important factors affecting the increasing utility of tracking tags in ecology has been their miniaturization, which has markedly expanded the range of species studied. Smaller tags can be used on a greater variety of species because biologists usually aim to have tags $<5 \%$ of the body weight of the animal to minimize their effects on animal behavior and survival (16). GPS tags with remote data readout have dropped from 250 to $20 \mathrm{~g}$ in about a decade (1 $\mathrm{g}$ logging
A

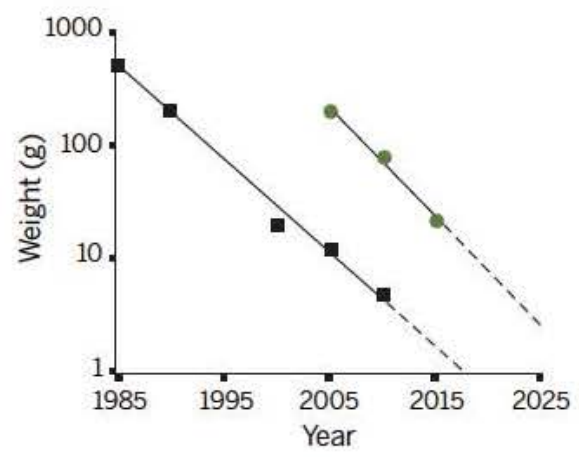

C

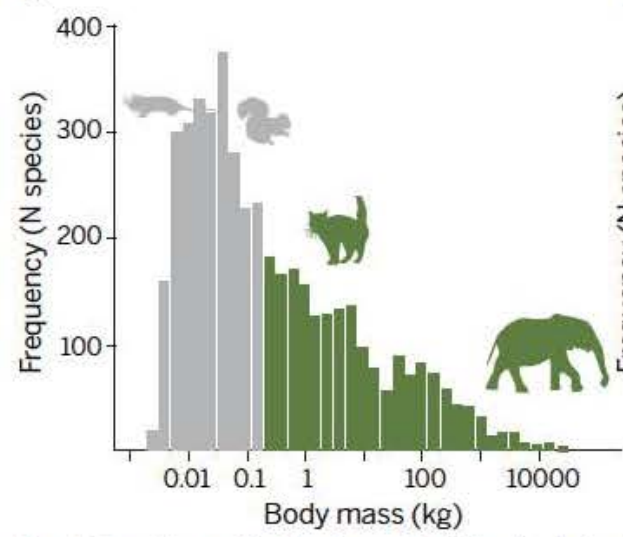

B

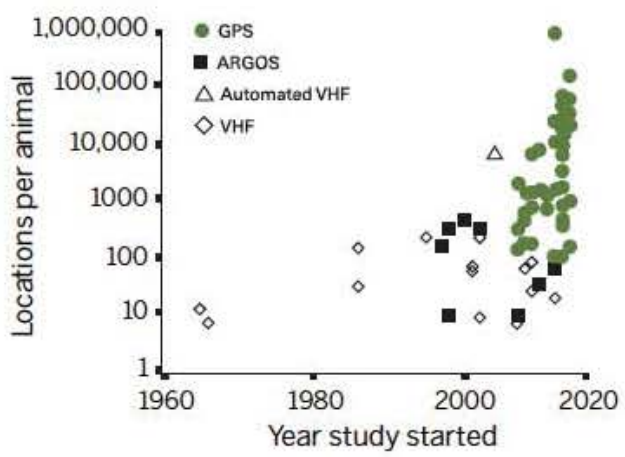

D

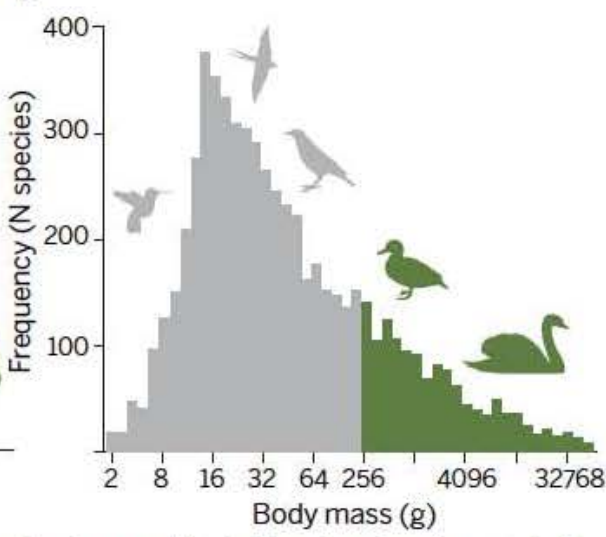

Fig. 3. Smaller and better tags. Rapid technological development has led to not only a decrease in the size of tags over time (A) but also a dramatic increase in the amount of data returned from each tagged animal (B). VHF tags are conventional "radio-tracking" technology where each animal location is typically collected manually via triangulation, although this process can be automated with base stations (115). Argos tags use Doppler shift to locate animals via satellite, which is less accurate than GPS but can presently be done with smaller tags. Data on tag size come from published studies, tag manufacturers websites, and our own data, whereas locations per animals come from 69 studies of birds and mammals (table S1) conducted or collaborated on by the authors. The continued decrease in tag size is essential for tracking the majority of small-mammal (C) and bird (D) species. Histograms show the body-mass distributions for all known birds and mammals [based on (7)], illustrating the proportion of species that can be tracked with GPS accuracy and global data readout with today's technology (15g) (green bars).

tags are also now available). At the same time, the temporal resolution of these tags has increased by approximately one order of magnitude every 5 years (Fig. 3). However, about $70 \%$ of bird spe cies and $65 \%$ of mammal species still cannot be tracked while on the move (as opposed to being recaptured to retrieve data loggers), including hundreds of small migratory birds and bats of great conservation concern and ecological im portance (8). Thus, the continued miniaturiza tion of technology remains a priority for the field, both to increase the number of small spe cies that can be safely tracked and to reduce the impact of tags on all species.

Most modern telemetry devices use the same electronic components as the mass consumer mar ket and thus have benefited from industry research aimed at decreasing size, increasing computing power, and improving battery technology (8). Re search focused on consumer electronics is sup plemented by groups developing technology specifically for animal tracking. For example, the ICARUS initiative is working to mount a new animal tracking antenna on the International Space Station that would allow smaller tags to send data back through the low orbit satellite (17), and the Sensor Gnome Network is currently managing $~ 1600$ very high frequency (VHF) track ing tags on one standard frequency, reporting the detection of tags at hundreds of locations across North America (18).

\section{Ethics and practicalities of} tagging animals

Since the first animal was fitted with an electro nic tag, the scientific community has been en gaged in an important discussion about ethical standards for this type of research (19). There is an inherent risk to each study animal whenever a tracking tag is attached, be it as a collar, har ness, or implant. Reducing the negative impacts of these tags is a priority not only for ethical rea sons, but also to ensure that the data collected accurately reflect the behavior of the species be ing studied. Extensive research has shown that the effects of tags on animals are generally unde tectable, or low, although there are also examples of severe impacts of particular tag types on par ticular species (16). Animal tracking research is typically regulated by institutional committees (i.e., Institutional Animal Care and Use Commit tee in the United States) to maintain high stan dards of animal care, which help drive constant methodological refinements to reduce the risks to animal subjects. The continued miniaturization of tracking tags supports this goal, as adding weight to animals is of primary concern. However, con tinued refinement of attachment methods is also a priority $(20)$

The ethics of animal tracking is a cost/benefit analysis, and scientists need to consider how they can offset the inherent costs of capture and tag ging by extending the benefits of their study. This includes designing studies that maximize the long term utility of data and addressing issues of important global concern that help confront the conservation challenges these same animals 
currently face. Finally, tracking data should be made easily available to policy makers, conserva tion organizations, and other scientists via online data repositories such as Movebank, EuroDeer, or WRAM (21 23). These archives for animal move ment data can greatly increase the scientific return on investment and promote animal welfare by reducing the need for new data collection.

\section{Detailed data, diverse questions}

Early ecology papers using VHF tracking typi cally addressed questions of animal home range size and habitat preference (24). High resolution location data and sensor streams allow scientists to consider the ultimate behavioral and ecolog ical mechanisms that underlie these movements, as well as the proximate internal and external factors that direct them (Fig. 4). There has also been a new push to identify the consequences of movement decisions, not only for individual ani
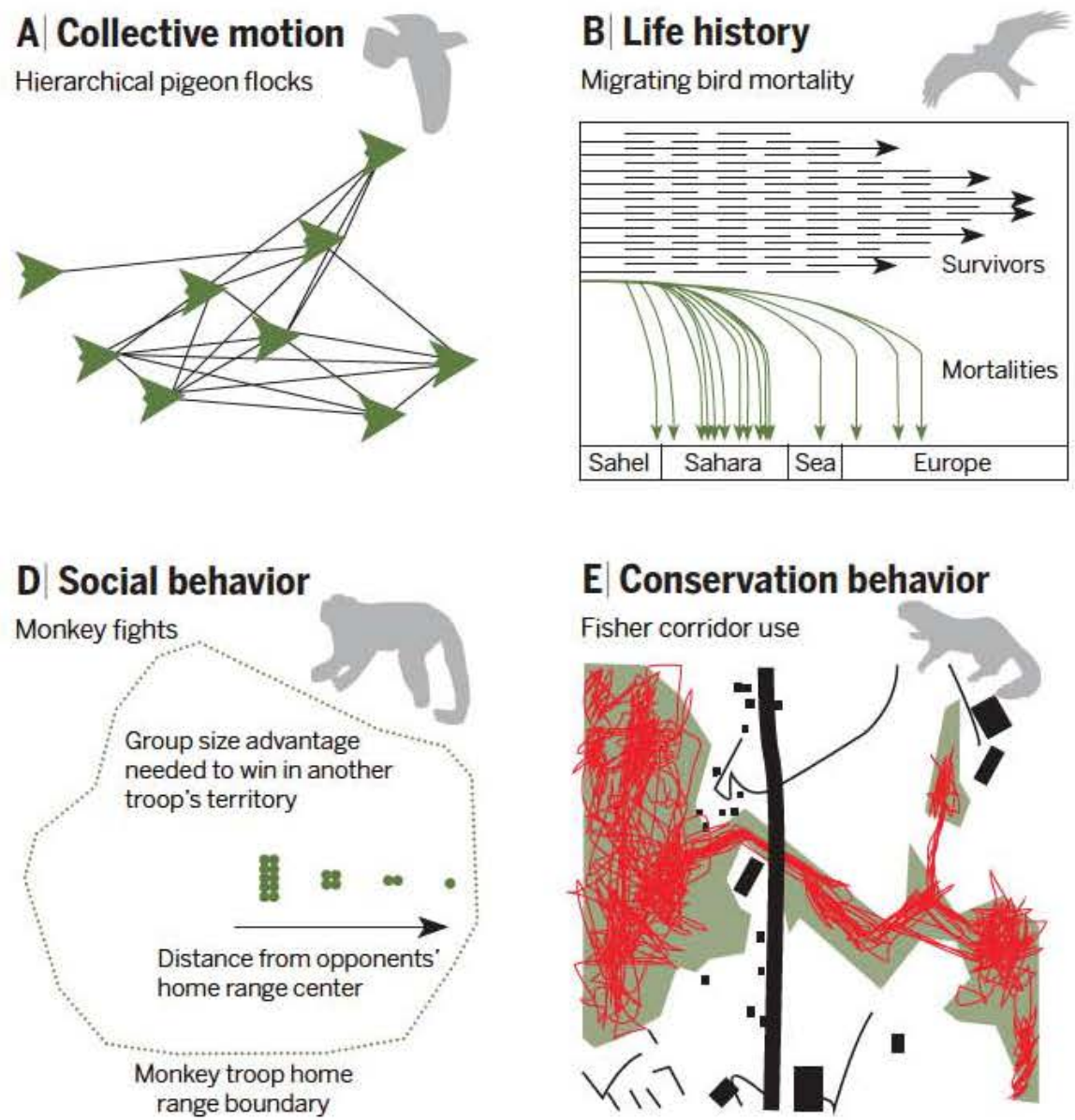

The large, continuous data streams from mod ern GPS tracking tags have revolutionized the study of animal space use, not only through the sheer size of data sets (3) but also by revealing an entirely new source of biological information about animal behavior that comes from connect ing sequential movement steps. Repeat locations along a movement trajectory are inherently non independent; traditional analytical approaches attempted to factor out this interdependence be fore describing an animal's space use (27). Modern approaches leverage new biological understand ing from this autocorrelation by integrating space and time to test hypotheses about animal move ment (28). Other approaches use high resolution movement and accelerometer information to char acterize behaviors, providing deeper insight and pre dictions into why animals visit different areas (15).

Deducing habitat preferences remains a prior ity for many tracking studies. Step selection

\section{Ecosystem services}

Hornbill seed dispersal

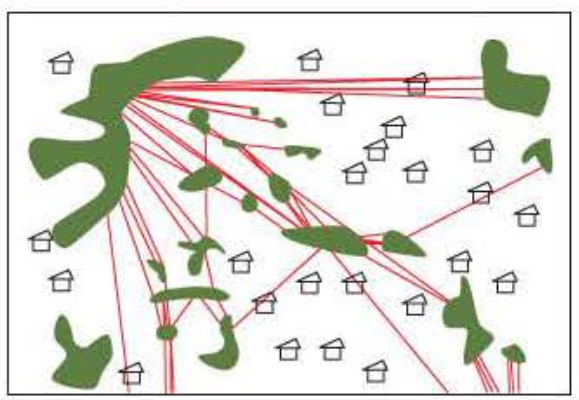

\section{F| Ecophysiology}

Cougar hunting

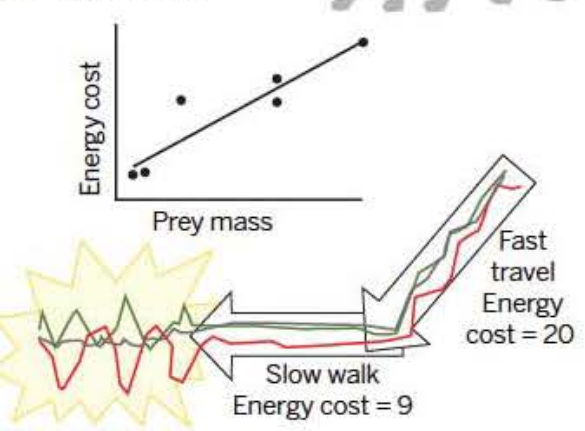

Pounce on deer

Energy cost $=65$

Fig. 4. Discoveries from tracking data. High-resolution animal tracking is leading to important discoveries in a variety of fields. (A) Studies of leadership in flocking pigeons documented a consistent hierarchy in following behavior, as representing by the gray lines (100). (B) Determining where migratory birds died showed that mortality rate was six times higher during migration than during the breeding or wintering grounds and that most of the 15 deaths (green lines) occurred in the Sahara desert (46). (C) Tracks of large hombills in South Africa (red lines) showed that they move between scattered fragments of natural vegetation (green patches), moving seeds with them, and highlight the importance of networks of smaller forests acting as stepping stones to connect far-flung larger forests (116). (D) Simultaneous tracks of competing

monkey groups allowed researchers to document the winners and losers of territorial contests and discover a substantial home-field advantage that allows smaller groups to fend off more numerous competing groups closer to the center of their range (93). (E) Fishers (red lines) moving through suburban Albany. New York, were found to repeatedly use movement corridors to connect smaller forest fragments (green area) into home ranges that were large enough to sustain their hunting needs (15). (F) Accelerometers combined with GPS tags allowed ecophysiologists to quantify the energy expended (arrows show direction of travel, and colored lines the animal's energy expenditure) by cougars attacking prey and show the cost of targeting large prey (inset graph) (80) 
functions offer an improvement over traditional compositional analyses by contrasting used against available habitat at each movement step, rather than across an animal's range (29). Further de velopment of these methods to integrate over multiple time scales would allow the evaluation of the importance of animal memory in move ment decisions $(30,31)$ and set the stage for ma jor breakthroughs in our understanding of the connections between animal cognition and ecol ogy. Furthermore, the integration of step selection functions with process based, mechanistic move ment models promises to link the social and en vironmental context of animal movement decisions to resulting patterns of space use and provide a framework for predicting changes in animal space use following perturbations (32).

Another notable advantage of GPS tags with global communication functionality is their abil ity to track dispersal or exploratory movements of study animals beyond their typical home ranges, information that traditional VHF tracking is usually unable to provide. Continuous, automated track ing can detect extraterritorial prospecting move ments in which individuals gather information before making decisions about mating, resource use, or long distance movements (33). Continu ous tracking also enables the precise description and study of juvenile dispersal, addressing ques tions of how young animals make decisions as they move through an environment that is com pletely foreign, and often hostile. Examples of amazing journeys of young animals that would have otherwise remained undocumented include a wolf that navigated through human dominated landscapes from Italy to France (32) and a leop ard that traversed three countries in southern Africa (34), demonstrating metapopulation link ages over large scales. If such megadispersals are regular features of a population or species, they can lead to evolutionary diversification, such as in Buteo hawks (35). Dispersing animals appear to have different habitat preferences than adults, although few studies have tracked enough dis persers to quantify this. Young elk disperse through higher quality habitat than found in typical adult home ranges (36), while dispersing African lions used completely different, and much riskier, hab itats than adults (37). These differences are crit ical for models attempting to identify and protect dispersal corridors between populations and should be a priority area for discovery in future GPS tracking studies. Additionally, this line of re search could empirically derive the movement metrics needed to evaluate if species will be able to discover and disperse into newly suitable hab itats that are rapidly changing with climate (38).

Large scale migration studies are nearly im possible with VHF tags. Early pioneers collected data through a series of cross country car chases behind tagged birds (39) or by flying slowly be hind them in light aircraft (40). Early satellite tracking provided global coverage for the migra tion of larger species, but with low accuracy ( $\pm 500 \mathrm{~m}$ up to $\pm 1000 \mathrm{~km}$ ) fixes recorded only once every few days. Modern GPS tags with solar pan els on migrating birds send location estimates recorded every second streaming live through the phone network (8). Maps of migratory fly ways can now plot exact routes across continents and identify critical stopover points (4I) (Fig. 1). Scientists are learning how birds make these amazing flights by integrating data from other sensors, including accelerometers, magnetometers, gyroscopes, pressure and temperature sensors, and even pitot tubes to measure air speed. We can now document birds' flight behavior as if they were airplanes carrying advanced aerospace technology. The results allow for mathematical descriptions of heretofore elusive behaviors such as the dynamic soaring of albatrosses (42).

One ultimate goal of the effort to describe an imal movement and its causes is to create models that can predict movements from the internal and external conditions an animal faces. Build ing from the movement ecology framework (I), this approach would integrate not only the hab itat preferences that have been the focus of most past research, but also parameters reflecting a species' movement abilities, sensory capacities, and memory. Finally, the importance of inter actions among animals will need to be addressed, including the intra and interspecific relation ships that tracking studies are just starting to explore. These integrative models will facilitate the testing of mechanistic hypotheses for animal movement and predict how they will respond to our rapidly changing environment.

\section{Consequences of movement for} individuals, populations, and ecosystems

Although most traditional movement research has focused on describing patterns and deducing their causes, a new generation of questions are emerging to evaluate the consequences of move ment across spatial scales.

Each animal's movements have immediate con sequences for its own life and death, making movement a behavioral adaptation subject to evolutionary selection. Few tracking studies simultaneously monitor reproductive fitness and space use; instead, they typically presume that animals' habitat preferences reflect fitness values (43). This assumption may be problematic, as one study that did monitor both reproductive output and movement patterns found that the most in tensely used habitats were not the best from the perspective of individual fitness, but lower quality areas that provided a refuge for nonreproductive animals (44). Tracking studies have a long his tory of identifying factors related to animal sur vival and are the primary way to identify the time, location, and cause of death. A review of mortality in large and medium sized North American mam mals, including over 2000 animals tracked until their death, highlighted the importance of humans (i.e., hunters and cars), which accounted for $52 \%$ of mortalities, compared to $35 \%$ that fell prey to natural predators (45). Satellite technology al lows us to monitor mortality of long distance migrants, which has recently been shown to be much higher during migration (46). The cumu lative effects of selective survival was noted by Sergio et al. (47), who showed a slow but steady improvement in migration performance with age, through a combination of differential survival and individual improvements.

When amplified across entire populations, ani mal movements determine the effect species have on ecosystems, because they determine the spa tial distribution of ecological forces like herbiv ory and predation or because movement itself provides biotic connectivity and associated eco system services. Studies of large carnivores offer the best examples of using GPS tracking to map the ecological effects of a species and test their importance. Studies of both temperate and trop ical systems have shown that prey avoid areas of high predator activity, especially ambush preda tors, but that selection of specific habitat features was more important (48). Moving animals can also provide ecosystem services by transporting other organisms, acting as vectors for diseases or dispersers for plant seeds and pollen. Because most seeds and pollen are too small to track di rectly, mechanistic models have been used to quan tify seed dispersal, showing how animal movement drives gene flow for plants (49).

Given that most new global diseases are zoo notic (i.e., spread through the interaction of wild life, livestock, and humans), there is extensive interest in understanding the movement of po tential disease vectors (50). A detailed, mechanistic understanding of the spatiotemporal interactions of wild animals with domestic animals, as well as among each other, is of high global priority (51). Similarly, it is essential to recognize that diseased animals could have altered behavior and move ment dynamics compared to healthy animals (52).

Finally, the movement of immigrant animals provides the genetic linkages necessary to main tain healthy populations, as well as colonizers necessary for establishing new ones. How dispers ing animals move through completely foreign landscapes is a key question that has generally been addressed by using tracking to characterize the overall movement and habitat preferences of species, which are then used to extrapolate likely dispersal routes. Although genetic relatedness among populations generally supports these habitat based predictions (53), they would be more robust if they considered actual trajectories of juvenile dispersers, which can differ dramatically from those of adults $(36,37)$. Integrative studies that quantify habitat use and track the journeys and fates of dispersers are the most compelling. One of the first examples of the metapopulation con cept, for example, emerged from a tracking study showing that subpopulations of cougar were sep arated by expanses of non cougar habitat, but linked by dispersers (54). GPS tracking has also documented the expansion of a species' range through dispersing animals [cougars (55)], the impacts of human policies on disperser survival [wolves (56)], and the importance of immigrants as genetic rescuers for inbred populations iso lated by habitat fragmentation (57). We anticipate a surge of research in the next few years high lighting the critical role of dispersing animals for understanding a wide range of ecological phenomena. 
New opportunities from integration with remote sensing

The increase in detail of animal movement brought about by improving GPS technology in the last decade has been matched, or even sur passed, by the rapid growth in remotely sensed or modeled products describing the world through which these animals move (Fig. 5). Animal be havior and ecology are intricately linked to en vironmental conditions that are dynamic in space and time. The ability to more directly and rigor ously link up predictors and response offers a powerful avenue for evaluating environmental connections in a hypothesis testing or predictive framework $(1,32)$. However, many technical, ana lytical, and conceptual challenges remain for the successful merging and simultaneous analysis of tracking and environmental data types (58).

Plotting animals' positions over a map to see what factors in the environment may affect their locations or movements has always been the first step of any animal tracking study. The individual specific and continuous nature of high resolution GPS animal trajectories, when combined with layers describing the environment, provides a unique lens for discovering how specific habitat elements or resources are used daily, seasonally, sequentially, at different life history stages, and for specific behaviors and purposes (59). Using largely categorical habitat characterizations, re search to date has helped identify critical habitat patches (60); study the impacts of fragmentation or barriers on movement patterns (61); model resource use (62), connectivity or wildlife corri dors (15), and critical migratory stop over or over wintering sites (63); or develop predictive models of suitable habitat for animal preservation or reintroduction (64). These applications have all been made possible by modeled information on climatic conditions [e.g., (65)] and through remote sensing based data layers on topography (SRTM: Shuttle Radar Topography Mission) and land cover (GlobCover, MODIS: Moderate Resolution Imaging Spectroradiometer, Landsat), which pro vide behaviorally and ecologically relevant infor mation at scales from several kilometers down to $30 \mathrm{~m}$.

Compared with spatial habitat information, weather has been integrated into fewer studies of animal movement. Some examples link local movements with information from nearby weath er stations, notably so for single events such as migratory onset (66). More recently, new tools have allowed the intersections of longer move ment paths with meteorological information, providing a continuous characterization of the conditions experienced by animals in three dimensional space, even as they cross the globe. This has allowed us to estimate the energetic costs or physiological constraints on flight, given temperature or altitude specific wind conditions (67), and identify behavioral strategies such as use of thermal or orographic uplift in flight (68). As the availability of temporally well resolved meteorological layers increases, providing 12 to 3 hourly information at global extent [although still with spatially coarse resolution (69)], we ex pect integration of weather data into movement models to become standard methodology for de termining proximate behavioral cues (69).

Although challenges for the spatial accuracy of GPS based animal locations (typically $<10 \mathrm{~m}$ ) re main, especially in closed habitat, these data cap ture the distribution and environmental niche for a species with accuracy unrivaled by other data types, and are less subject to sampling biases (70). At a regional scale, remote sensing products such as ASTER (Advanced Spaceborne Thermal Emission and Reflection Radiometer) and SPOT (Satellite Pour l'Observation dela Terre) have the potential to match this resolution with informa tion on habitat condition and resources (7T), and where available, LIDAR (Light Detection and Ranging) and hyperspectral remote sensing data (72) allow us to extend our information to in clude vegetation structure. Other satellite or aerial survey data, such as those integrated into Google Earth (Quickbird, SPOT, WorldView, IKONOS,
RapidEye), offer additional snapshots of meter level habitat details but usually lack the spectral resolution needed for detailed habitat character izations and tend to be restricted to small spatio temporal footprints. A particularly exciting prospect is the increasingly detailed and complete envi ronmental annotation of movement paths. MODIS sensors have the potential to provide global in formation on greenness and other land surface attributes down to 8 day or even daily frequency, and researchers have begun to successfully use these to relate movement to resource availability (73). Remote sensing supported predictions of climate conditions in daily and $1 \mathrm{~km}$ resolution (74) hold the promise to extend such annotations to ecologically even more meaningful variables.

Given the growth in amount and detail of tracking and remote sensing data, combined with advances in analysis methods and tools support ing species distribution modeling (75) and ad dressing data nonindependence in habitat analysis $(76,77)$, we expect to see a future with more in tegrative modeling of animal location and behav ior in multidimensional climate and environment space. The data management challenges for in tersecting such fine grained levels of animal and environmental information are substantial. For tunately, Web based infrastructures such as Move bank $(23,78)$ or Map of Life (79) have automated many of the steps needed to access and integrate these data types. Tracking data combined with environmental sensors are thus poised to offer an increasingly thorough, quantitative, and in tegrative understanding of the environmental underpinning of animal movement and behavior and their reliable prediction in space and time.

\section{New opportunities from multi-individual} and multispecies tracking

Multi sensor tracking tags are not only changing what we know about where animals go, they are also transforming what we know about how an imals interact. Rare, and often cryptic, contacts with con and heterospecifics trigger some of the
A

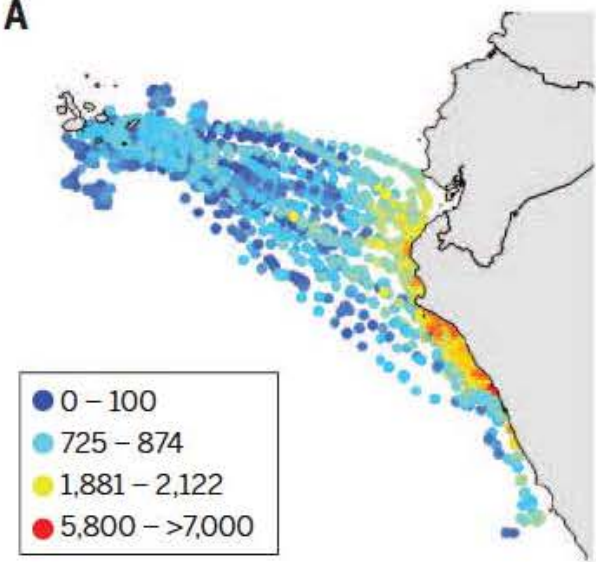

B

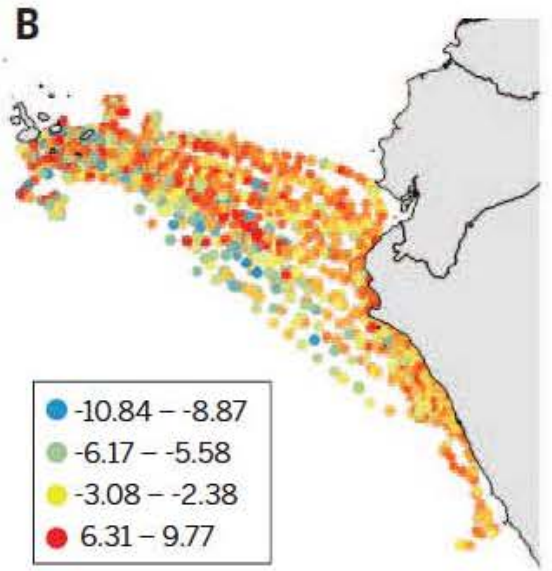

C

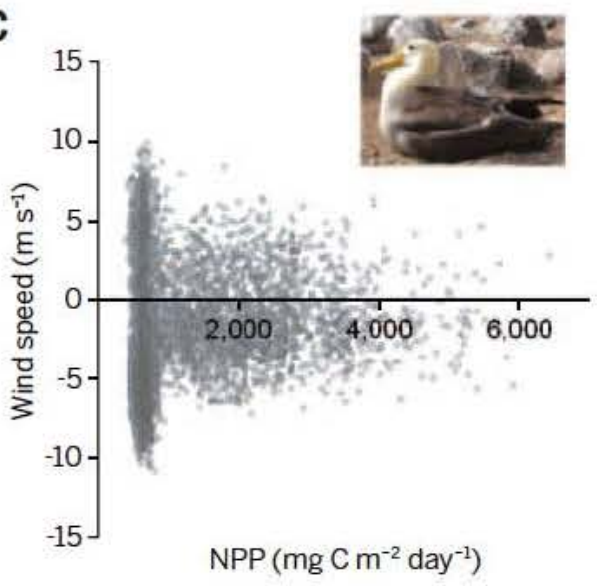

Fig. 5. Tracking an mals in environment space. Spatial movements of nine Galapagos Albatross (Phoebastria irrorata) from June to September 2008 annotated with net primary productivity (NPP) (from 8-day MODIS ocean productivity) (A) and tail-wind data (B) (from the National Centers for Environmental Prediction Reanalysis 2 data). (C) The same locations in two-dimensional environment space. Birds seek out high-NPP, low-wind foraging areas near the coast, but cross high-wind regions in transit. For details, see (78) and movie S1. 
most important events in animals' lives, but are often impossible to study with observational tech niques. High resolution, multi individual GPS tracking provides new opportunities to "see" such interactions and connect the behavior of individ uals to emergent patterns of group, community, and population movement.

Predator prey interactions are one area where high resolution animal tracking is already making substantial contributions. A suite of recent studies using GPS in conjunction with accelerometers to track large felids has provided extremely detailed information about the dynamics of predation, documenting the energetics of sit and wait (80) and active pursuit hunting strategies (81), detail ing the locomotor performance of hunting cheetah (82), and describing how cheetah pursuit behavior changes depending on prey species (83). Simulta neous tracking of caribou, moose, and wolves in anthropogenically disturbed habitats has revealed that the network connectivity of resource patches affects both the spatial dynamics of large herbi vores and the hunting strategies of their predators (84). Simultaneous tracking has also been used to assess the feeding costs of antipredator be havior (85). However, caution is needed when drawing conclusions from such studies, as mis matches between sampling protocols and biolog ical phenomena of interest can complicate inference. For example, while a recent study of wolf elk interactions concluded that encounters were rare and thus that wolves had little direct influence on elk behavior (86), a reanalysis suggested that the interactions were seriously underestimated because the interval between GPS fixes was long relative to the duration of interactions and be cause uncollared wolves in the population were not properly accounted for (87). This example highlights the importance of matching the scale of data collection with the behavior being studied and the value of very high temporal resolution tracking data for interaction studies.

Multi individual tracking is also shedding light on how competitive dynamics organizes space use and resource access in animal communities. Attraction and avoidance can be inferred from concurrent movements of neighboring animals $(88,89)$, providing important insight into the be havioral processes underlying the territorial dy namics of individuals $(90,91)$ and groups $(88,92)$. For example, simultaneous tracking has revealed that the outcome of competitive interactions be tween neighboring primate social groups depends more strongly on the location of the encounter than the relative size of the groups and has docu mented the costs of losing territorial interactions (93, 94, 95). Although mechanistic home range models provide a framework for investigating how indirect interactions among animals shape patterns of space use [i.e., scent marks (96); vo calizations (97)], it is less clear how to integrate direct, dynamic interactions such as fights and territorial displays (98), and this remains an area of active, and much needed, research (99).

The ability to monitor the movements of many free ranging animals with submeter accuracy and continuous resolution is also influencing the study of collective animal behavior, allowing data collection to move from the lab into the field. High resolution tracking of entire pigeon flocks reveals that some individuals have more influence over collective movement decisions than others, leading to strong, consistent leadership hierarchies (100). "Rules of interaction" extracted from the correlation structure of the trajectories of pairs of homing individuals suggest that speed, rather than dominance, is the key factor underlying leadership (101, 102). Whole group GPS tracking is also providing insight into the self organization of animal groups. Using a herding dog to provoke changes in the geometry of sheep groups, King and colleagues (103) show that the selfish herd effect emerges because individual sheep respond to global, rather than local, cues of group struc ture when their perceived predation risk increases. Species' behavioral and ecological character istics, and how they may respond to environ mental change, are affected by plasticity and adaptation set at the individual and population scale (104). Foraging behaviors and associated ecological niches have been shown to sometimes exhibit substantial individual differences, with far reaching ecological and evolutionary consequences (105). Multi individual tracking opens up new op portunities to quantify this individual variation in space use and associated niches for animals in the field and over larger scales than close observation designs allow. However, collaboration is perhaps as important as improving technology to our understanding of plasticity in animal movement. By using metadata standards and sharing across studies, new questions can be addressed with better statistical power about changes in animal movement over larger temporal and spatial scales $(21,106)$.

\section{Animal tracking to monitor a changing planet}

With global change causing ongoing and accel erating loss of biodiversity, a more mechanistic and detailed understanding of the space require ments and environmental associations of ani mals is pressing. Tracking data, especially when combined with remote sensing and detailed cli mate layers, has the potential to play a vital role, complementing biodiversity information gath ered from museum or citizen science efforts (70). The high resolution locations from tracking can contribute to essential biodiversity variables ad dressing species distributions (107) and support biodiversity monitoring and assessment as man dated under the Convention on Biological Diversity and the Intergovernmental Platform on Biodiver sity and Ecosystem Services. The spatiotemporally detailed and real time nature of GPS tracking data supports the use of tagged animals as pas sive sensors of the environment to document how ongoing changes are affecting species' distribu tion and ecological function. In particular, species with large movements may offer an opportunity to monitor specific biological impacts of ongoing environmental change for example, if they are found to avoid previously used locations, habitat, or migratory stopover sites.
The roles of tracked animals as sensors of en vironmental change can extend to more active uses by which animals directly sense the environment. Recent examples include the monitoring of arctic temperatures and vegetation changes during cli mate change (108) and documenting ocean cur rents (109), and in the future may allow for the estimation of altitudinal wind profiles based on bird flight parameters. Tagged animals as sen sors could be especially useful as environmental sensing agents in areas plagued by security or logistical difficulties, or for phenomena not di rectly detectable by remote sensing; for example, the accumulation of migratory European storks migrating in the African Sahel could indicate where desert locust swarms develop each year (Fig. 1). Similarly, animals may even be able to anticipate upcoming natural disasters and change their move ments on the basis of this knowledge $(110,111)$.

\section{Achievements and future vision}

Over the last 5 years, the field of animal tracking has climbed a steep trajectory of data and knowl edge; we think that it is approaching a transfor mational point from us learning about animals, to having animals teach us about our world. The concept of animals as in situ sensors of our en vironment has only begun to be explored in the terrestrial realm, although it has a strong history in marine tracking (112). We suggest that a new approach that views animals as naturally evolved sensors of the environment has the potential to help us monitor the planet in completely new ways, especially if coordinated through a massive multi individual monitoring program. Many of the components for this program are already in use for individual projects, including live data streams, community data standards and sharing frameworks, and tools for environmental data in tegration $(14,23,78)$. Additional improvement in animal mounted sensors, especially continuing miniaturization, is still needed to increase the variety of animals that can be tagged and the sen sors they can carry, and to further minimize the impact of tags on animals' daily lives (8).

A massive multi individual monitoring program would allow a quorum sensing of our planet (113), using a variety of species to tap into the diversity of senses that have evolved in different animal groups. Connecting these individual level telem etry data with population level monitoring could identify mechanisms driving population increases or declines, and identify the consequences to the environments in terms of ecosystem services. Ecological forecasting based on predictable ani mal movements could help us anticipate and mitigate environmental problems. However, doc umenting unpredictable movements might be just as important showing how animals adapt to changing conditions in unpredictable ways offers a lens to the future of animal ecology in the Anthropocene.

\section{REFERENCES AND NOTES}

1. R. Nathan et al., A movement ecology paradigm for unifying organismal movement research. Proc. Natl. Acad. Sci. U.S.A. 105, 1905219059 (2008). doi: 10.1073/pnas.0800375105; pmid: 19060196 
2. C. Kremen et al., Pollination and other ecosystem services produced by mobile organisms: A conceptual framework for the effects of land use change. Ecol Lett. 10, 299314 (2007). pmid: 17355569

3. F. Urbano et al., Wildilife tracking data management: A new vision. Philos. Trans. R. Soc. B Biol. Sci. 365, 21772185 (2010).

4. J. Li et al., Social information improves location prediction in the wild. AAAI Workshop (2015).

5. A. L. Vyssotski et al., EEG responses to visual landmarks in flying pigeons. Curr. Biol. 19, 11591166 (2009). doi: 10.1016/ j.cub 2009.05.070; pmid: 19559612

6. M. A. Hanson et al., Body area sensor networks: Challenges and opportunities. Computer 42, 5865 (2009). doi: 10.1109/ MC. 2009.5

7. R. D. Lord Jr., F. C. Bellrose, W. W. Cochran, Radiotelemetry of the respiration of a flying duck. Science 137, 3940 (1962). doi: $10.1126 /$ science. 137.3523 .39 ; pmid: 17774128

8. E. Bridge et al., Technology on the move. Bioscience 61. 689698 (2011), doi: 10.1525/bio.2011619.7

9. D. D. Brown, R. Kays, M. Wikelski, R. Wilson, A. P. Klimley, Observing the unwatchable through acceleration logging of animal behavior. Anim. Biotelemetry 1, 20 (2013). doi: $101186 / 20503385120$

10. C. Signer et al., A versatile telemetry system for continuous measurement of heart rate, body temperature and locomotor activity in free ranging ruminants. Meth. Ecol. Evol. 1 . 7585 (2010). doi: $10.1111 /$;.2041 210x.2009.00010.x pmid: 22428081

11. N. C. Rattenborg et al., Sleeping outside the box: Electroencephalographic measures of sleep in sloths inhabiting a rainforest. Biol. Lett. 4, 402405 (2008) doi: 10.1098/rsbl.2008.0203; pmid: 18482903

12. R. J. Moll, J. J. Millspaugh, J. Beringer, J. Sartwell, Z. He A new 'view' of ecology and conservation through animal borne video systems. Trends Ecol. Evol. 22, 660668 (2007). doi: 10.1016/j.tree.2007.09.007; pmid: 18006184

13. A. Matthews et at., The success of GPS collar deployments on mammals in Australia. Aust. Mammal 35, 6583 (2013). doi: 10.1071/AM12021

14. J. Wall, G. Wittemyer, B. Klinkenberg, I. Douglas Hamilton, Novel opportunities for wild life conservation and research with real time monitoring. Ecol. Appl. 24, 593601 (2014). doi: 10.1890/13 1971.1; pmid: 24988762

15. S. LaPoint, P. Gallery, M. Wikelski, R. Kays, Animal behavior cost based corridor models, and real corridors. Landscape Ecol 28.1615 1630 (2013). doi: 101007/s10980 01399100

16. D. L. Murray, M. R. Fuller, in Research Techniques in Animal Ecology: Controversies and Consequences. L. Boitani, T. K. Fuller, Eds. (Columbia Univ. Press, New York, 2000). pp. 1564 .

17. ICARUS Initiative, International Cooperation for Anima Eesearch Using Space, (available at http:/ /icarusinitiative.org

18. Sensor Gnome (2014), available at www.sensorgnome.org)

19. E. Benson, Wred Widerness: Techndogies of Tracking and the Making of Modern Wildlife (John Hopkins Univ. Press, Baltimore, MD, 2010)

20. S. P. Vandenabeele, R. P. Wilson, M. Wikelski, New trackin philosophy for birds. Front. Ecol. Environ 11, 1012 (2013). doi: $10.1890 / 13$.WB.002

21. F. Cagnacci, F. Urbano, Managing wildlife: A spatial irformation system for GPS collars data. Environ Model. Softw 23. 957959 (2008). do: 10.1016/jenvsoft 2008.01.003

22. H. Dettki, M. Brode, I. Clegg, T. Giles, J. Hallgren, Wireless Remote Animal Monitoring (WRAM) A new international database e infrastructure for management and sharing of telemetry sensor data from fish and. Int. Congr. Env. Model. Softw. 7 (2014).

23. M. Wikelski, R. Kays, Movebank: Archive, analysis and sharing of animal movement data. World Wide Web electronic publication.; www.movebank.org (2010).

24. J. J. Millspaugh et al., in The Wildife Techniques Manua: Volume 1: Research, N. J. Silvy, Ed. (Johns Hopkins Univ. Press, Baltimore, MD, ed. 7, 2012), pp. 258283.

25. R. A. Cheke, J. A. Tratalos, Migration, patchiness, and population processes illustrated by two migrant pests. Bioscience 57, 145 (2007). doi: 10.1641/8570209

26. J. Y. Takekawa et al., Migration of waterfowl in the East Asian flyway and spatial relationship to HPAI H5N1 outbreaks. Avian Dis. 54 (suppl.), 466476 (2010). doi: 10.1637/ 8914043009 Reg.1; pmid: 20521681

27. S. R. De Solla, R. Bondurianski, R. J. Brooks, Eliminating autocorrelation reduces biological relevance of home range estimates. I. Anim. Ecol. 68, 221234 (1999). doi: 101046/ $13652656.1999 .00279 \times$

28. S. Benhamou, L. Riotte lambert, Beyond the utilization distribution: Identifying home range areas that are intensively exploited or repeatedly visited. Ecol Model 227. 112116 (2012), doi: 10.1016/iecolmodel 2011.12015

29. H. Thurfjell, S. Ciuti, M. S. Boyce, Applications of step selection functions in ecology and conservation. Mov. Ecol. 2 , 4 (2014). doi: $10.1186 / 205139332$ 4; pmid: 25520815

30. W. F. Fagan et al, Spatial memory and animal movement. Ecol. Lett. 16. 13161329 (2013). doi: 10.1111/ele.12165; pmid: 23953128

31 T. Avgar, R. Deardon, J. M. Fryxell, An empirically parameterized individual based model of animal movement, perception, and memory. Ecol. Model. 251, 158172 (2013) do: $10.1016 /$ /.ecolmodel.2012.12.002

32. P. Ciucci, W. Reggioni, L. Maiorano, L. Boitani, Long Distance dispersal of a rescued wolf from the Northern Apennines to the Western Alps. J. Widll. Manage. 73, 13001306 (2009). da: $10.2193 / 2008510$

33. A. Ponchon et al., Tracking prospecting movements involved in breeding habitat selection: Insights, pitfalls and perspectives. Methods Ecol. Evol. 4, 143150 (2013). do: $101111 / 12041210 \times 2012.00259 \times$

34. J. Fattebert, T. Dickerson, G. Balme, R. Slotow, L. Hunter, Long distance natal dispersal in leopard reveals potentia for a three country metapopulation. S. Aft. J. Widl. Res 43 . 6167 (2013). doi: 103957/056.043.0108

35. K. Bildstein, Raptor migrations in the Neotropics: Patterns, processes, and consequences. Ornitol. Neotrop. 15, 8399 (2004).

36. J. Killeen et al.. Habitat selection during ungulate dispersa and exploratory movement at broad and fine scale with implications for conservation management. Mov. Ecol 2, 15 (2014). doi: $101186 / 54046201400154$

37. N. B. Ellot, S. A. Cushman, D. W. Macdonald, A J. Loveridge, The devil is in the dispersers: Predictions of landscape connectivity change with demography. J. Appl. Ecol. 51 11691178 (2014), doi $101111 / 1365266412282$

38. C. A. Schioss, T. A. Nuñez, J. J. Lawler, Dispersal will limit ability of mammals to track climate change in the Western Hemisphere. Proc. Natl. Acad. Sci. U.S.A. 109, 86068611 (2012) doi: 101073/pnas.1116791109: pmid: 22586104

39. W. W. Cochran, C. G. Kjos, Wind drift and migration of thrushes: A telemetry study. III. Nat. Hist. Surv. Bull. 33 297330 (1985)

40. M. Wikelski et al. Simple rules guide dragonfly migration. Biol Lett. 2. 325329 (2006), doi: 10.1098/rsbt.2006.0487; pmid: 1748394

41 F. Qian et al., Migration routes and stopover sites of Black necked Cranes determined by satellite tracking. 1. Field Ornithol 80, 1926 (2009). doi: 10.111 $15579263.2009 .00201 . x$

42. G. Sachs, J. Traugott, A. P. Nesterova, F. Bonadonna, Experimental verification of dynamic soaring in albatrosses. 1. Exp. Biol. 216, 42224232 (2013), doi: $101242 /$ jeb. 085209; pmid: 24172888

43. J. M. Morales et al., Building the bridge between animal movement and population dynamics. Philos. Trans. R. Soc Lond. B Biol. Sci. 365, 2289 2301 (2010). doi: 10.1098/ rstb. 2010.0082; pmid: 20566505

44. A. Mosser, J. M. Fryxell, L. Eberly, C. Packer, Serengeti rea estate: Density vs. fitness based indicators of lion habitat quality. Ecol. Lett. 12, 10501060 (2009). doi: 10.1111 / j.1461 0248.2009 01359.x; pmid: 19708970

45. C. Collins, R. Kays, Causes of mortality in North American populations of large and medium sized mammals. Anim. Conserv. 14, 474483 (2011), doi: 10.1111/ j.1469 1795.2011.00458.x

46. R. H. G. Klaassen et al., When and where does mortality occur in migratory birds? Direct evidence from long term satellite tracking of raptors. J. Anim. Ecol. 83, 176184 (2014), doi: 10.1111/1365 265612135; pmid: 24102110

47. F. Sergio et al., Individual improvements and selective mortality shape lifelong migratory performance. Nature 515 410413 (2014). do: 10.1038 /naturel3696; pmid: 25252973

48. M. Thaker et al., Minimizing predation risk in a landscape of multiple predators: Effects on the spatial distribution of African ungulates. Ecology 92, 398407 (2011). doi: 10.1890/ 10 01261; pmid: 21618919

49. M. C. Cortes, M. Uriarte, Integrating frugivory and animal movement: A review of the evidence and implications for scaling seed dispersal. Bia. Rev. Camb. Philos. Soc. 88 .
255272 (2013). doi: $10.1111 / j 1469185 \times 2012.00250 \times$ : pmid: 23136896

50. S. H. Newman et al., Eco virological approach for assessing the role of wild birds in the spread of avian influenza H5N1 along the Central Asian Flyway. PLOS ONE 7, e30636 (2012) doi: 10.1371/journal pone.0030636; pmid: 22347393

51 S. H. Newman, J. H. Epstein, L. M. Schloegel, The nature of emerging zoonotic diseases: Ecology, prediction, and prevention. MLO Med. Lab. Obs. 37, 10 11, 14 16, 1819 , quiz 2021 (2005), pmid: 16156542

52. J. A. van Gils et al., Hampered foraging and migratory performance in swans infected with low pathogenic avian influenza A virus. PLOS ONE 2, e184 (2007). doi: 10.1371/ journal.pone. 0000184 ; pmid: 17264886

53. A. B. A. Shafer et al., Habitat selection predicts genetic relatedness in an alpine ungulate. Ecology 93, 13171329 (2012). doi: 101890/11 08151; pmid: 22834373

54. L L Sweanor, J. A. Logan, M. G. Hornocker, Cougar dispersal patterns, metapopulation dynamics, and conservation. Conserv. Biol. 14, 798808 (2000). doi: 10.1046/ j.1523 $1739.2000 .99079 . x$

55. D. J. Thompson, J. A. Jenks, Dispersal movements of subadult cougars from the Black Hills: The notions of range expansion and recolonization. Ecosphere 1, art8 (2010). doi: 10.1890/ES10 00028.1

56. $\mathrm{L}$ Kojola et a... Dispersal in an expanding wolf population in Finland. J. Mammal. 87, 281286 (2006). doi: 10.1644/ 05 MAMM A 061R2.1

57. S. P. D. Riley et al., Individual behaviors dominate the dynamics of an urban mountain lion population isolated by roads. Curr. Biol. 24, 19891994 (2014). doi: 10.1016/ cub.2014.07.029; pmid: 25131676

58. C. Kuenzer et al., Earth observation satellite sensors for biodiversity monitoring: Potentials and bottlenecks. Int I Remote Sens. 35, 65996647 (2014). doi: 10.1080/ 01431161.2014 .964349

59. J. M. Gaillard et al., Habitat performance relationships: Finding the right metric at a given spatial scale. Philos. Trans. R. Soc. Lond. B Biol. Sci. 365, 22552265 (2010). doi: 10.1098/rstb.2010.0085; pmid: 20566502

60. J. Lenz et al., Seed dispersal distributions by trumpeter hornbills in fragmented landscapes. Proc. R. Soc. B Biol. Sci. 278, 22572264 (2010)

61. G. Kerth, M. Melber, Species specific barrier effects of motonway on the habitat use of two threatened forest living bat species. Biol. Conserv. 142, 270279 (2009). doi: 10.1016/i.biocon.2008.10.022

62. J. D. Forester et al., State space models link elk movement patterns to landscape characteristics in Yellowstone National Park. Ecol. Monog. 77, 285299 (2007). doi: 10 1890/06 0534

63. C. Trierweiler et al., Migratory connecbivity and population specific migration routes in a long distance migratory bird Proc. R. Soc. Land. B Biol. Sci. 281 (2014 doi: 10.1098/ rspb.2013.2897

64. T. M. Donovan et al., Quantifying home range habitat requirements for bobcats (Lynx rufus) in Vermont. USA. Biol. Conserv. 144, 27992809 (2011). doi: 10.1016/ biocon.2011.06.026

65. M. New, M. Hulme, P. Jones, Representing twentieth century space time climate variability. Part it. Development of 190196 monthly grids of terrestrial surface climate. J. Clim. 13 22172238 (2000), doi: $10.1175 / 15200442(2000) 013<2217$ RTCSTC $>2.0 .002$

66. N. Sapir, M. Wikeiski, R. Avissar, R. Nathan, Timing and flight mode of departure in migrating European bee eaters in relation to multi scale meteorological processes. Behav. Ecol. Socicbiol. 65, 13531365 (2011). do: 10.1007/s00265 $0111146 \mathrm{x}$

67. R. E. Gill et al., Extreme endurance flights by landbirds crossing the Pacific Ocean: Ecological corridor rather than barrier? Proc. Biol. Sci. 276, 447457 (2009) pmid: 18974033

68. G. Bohrer et al., Estimating updraft velocity components over large spatial scales: Contrasting migration strategies of golden eagles and turkey vultures. Ecol. Lett. 15, 96103 (2012). doit $10.1111 / 114610248201101713 . x$; pmid: 22077120

69. C. Kummerow, W. Barnes, T. Kozu, I. Shive, I Simpson, The Tropical Rainfall Measuring Mission (TRMM) sensor package. J. Atmos. Ocean. Technol. 15, 809817 (1998). doi: 10.1175/ 1520 0426(1998) 015<0809:TTRMMT >2.0.C0;2

70. W. Jetz, J. M. McPherson, R. P. Guralnick, Integrating biodiversity distribution knowledge: Toward a giobal map of life. Trends Ecol Evol. 27, 151 159 (2012), doi: 10.1016/ i.tree.201109.007; pmid: 22019413 
71. M. R. Recio, R. Mathieu, M. C. Latham A. D. M. Latham, P. J. Seddon, Quantifying fine scale resource selection by introduced European hedgehogs (Erinaceus europaeus) in ecologically sensitive areas. Biol. Invasions 15, 18071818 (2013). doi: 10.1007/s105300130410 5

72. S. J. Goetz, M. Sun, S. Zolkos, A. Hansen, R. Dubayah, The relative importance of climate and vegetation properties on patterns of North American breeding bird species richness. Environ. Res. Lett 9. 034013 (2014). doi: 10.1088/ $17489326 / 9 / 3 / 034013$

73. C. Trierweiler et al, A Palaearctic migratory raptor species tracks shifting prey availability within its wintering range in the Sahel. J. Anim. Ecol. 82, 107120 (2013). doi: 10.1111/ j.1365 26562012.02036x: pmid: 23137184

74. B. Parmentier et al. An assessment of methods and remote sensing derived covariates for regional predictions of $1 \mathrm{~km}$ daily maximum air temperature. Remote Sens. 6,86398670 (2014), doi: $10.3390 / \mathrm{rs6098639}$

75. C. Calenge, The package "adehabitat" for the R software: A tool for the analysis of space and habitat use by animals. Ecol. Model. 197, 516519 (2006). doi: 10.1016/ j.ecolmodel 2006.03 .017

76. J. Fieberg. J. Matthiopoulos, M. Hebblewhite, M. S. Boyce. 1. L. Frair, Correlation and studies of habitat selection: Problem, red herring or opportunity? Philos. Trans. R. Soc. Lond. B Biol. Sci. 365, 22332244 (2010), doi: 10.1098/ rstb. 2010.0079; pmid: 20566500

77. B. Kranstauber, R. Kays, S. D. Lapoint, M. Wikelski, K. Safi, A dynamic Brownian bridge movement model to estimate utilization distributions for heterogeneous animal movement. J. Anim. Ecol. 81, 738746 (2012), doi: 10.1111 j.1365 26562012.01955.x; pmid: 22348740

78. S. Dodge et at. The environmental data automated track annotation (Env DATA) system: Linking animal tracks with environmental data. Mov. Ecol. 1, 3 (2013). doi: 101186/ 2051393313 ; pmid: 25709817

79. Map of Life (2014), available at http://mol.org.

80. T. M. Williams et al. Instantaneous energetics of puma kills reveal advantage of felid sneak attacks. Science 346, 8185 (2014). doi: $10.1126 /$ science 1254885 ; pmid: 25278610

81 D. M. Scantlebury et al., Flexible energetics of cheetah hunting strategies provide resistance against kleptoparasitism Science 346,79 81 (2014) doi: $10.1126 /$ science. 1256424 ; pmid: 25278609

82. J. W. Wilson et al., Cheetahs, Acinonyx jubatus, balance turn capacity with pace when chasing prey. Biol Lett. 9, 20130620 (2013). doi: 10.1098/rsbl 2013.0620; pmict 24004493

83. A. M. Wilson et al., Locomotion dynamics of hunting in wild cheetahs. Nature 498, 185189 (2013), doi: 10.1038/ nature12295: pmid: 23765495

84. N. Courbin, D. Fortin, C. Dussault, R. Courtois, Logging induced changes in habitat network connectivity shape behavioral interactions in the wolf caribou moose system. Ecol Monogr. 84, 265285 (2014). doi: 101890/12 2118.1

85. F. Barnier et al., Diet quality in a wild grazer declines under the threat of an ambush predator. Proc. Biol. Sci. 281, 20140446 (2014). doi: 101098/rspb.2014.0446; pmid: 24789903

86. A. D. Middleton et al., Linking anti predator behaviour to prey demography reveals limited risk effects of an actively hunting large carnivore. Ecol. Lett. 16, 10231030 (2013). doi: 101111/ele.12133; pmid: 23750905

87. S. Creel, J. A. Winnie Jr., D. Christianson, Underestimating the frequency, strength and cost of antipredator responses with data from GPS collars: An example with wolves and elk. Ecol. Evol. 3, 51895200 (2013). doi: 10.1002/ece3.896: pmid: 24455148

88. Z. Li, T. Kin, H. Lei, R. Kays, M. C. Crofoot, Attraction and avoidance detection from movements. Proc. 2014 int. Cont. Very Large Data Bases, 157168 (2013).

89. J. A. Long, T. A. Nelson, S. L. Webb, K. L. Gee, J. A. Long, T. A. Nelson, S. L. Webb, K. L. Gee, A critical examination of indices of dynamic interaction for wildlife telemetry studies. 1. Anim Ecol 83, 12161233 (2014), doi: 10.1111 13652656.12198

90. S. Benhamou, M. Valeix, S. Chamaillé Jammes, D. W. Macdonald, A. J. Loveridge, Movement based analysis of interactions in African lions. Anim. Behav. 90, 171180 (2014). doi: 10.1016 janbehav.2014.01.030

91 M. Lohrs, P. Kappeler, Simultaneous GPS tracking reveals male associations in a solitary carnivore. Behav. Ecol. Sociobiol. 67. 1731.1743 (2013). doi: 101007/s00265 0131581 y

92. L. Alba Mejia, D. Caillaud, O. Montenegro, P. Sánchez Palomino, M. Crofoot, Spatiotemporal interactions among three neighboring groups of free ranging white footed tamarins (Saguinus leucopus) in Colombia. Int. J. Primatol. 34 12811297 (2013). doi: 10.1007/s107640139740 6

93. M. C. Crofoot, I. C. Gilby, M. C. Wikelski, R. W. Kays, The home field advantageInteraction location outweighs the competitive advantage of numerical superiority in Cebus capucinus intergroup contests. Proc. Nati. Acad. Sci. U.S.A. 105.577 581 (2008). doi: 101073/pnes.0707749105x pmid: 18184811

94. A. C. Markham, S. C. Alberts, J. Altmann, Intergroup conflict: Ecological predictors of winning and consequences of defeat in a wild primate population. Anim. Behav. 84, 399403 (2012). do: 10.1016// anbehav.2012.05.009; pmid: 22837555

95. M. C. Crofoot, The cost of defeat: Capuchin groups travel further, faster and later after losing conflicts with neighbors. Am. J. Phys. Anthropol. 152, 7985 (2013). doi: $10.1002 /$ ajpa 22330; pmid: 23900797

96. P. R. Moorcroft, M. A. Lewis, Mechanistic home range analysis. Monogr. Popul Biol 43, 208 (2006)

97. J. R. Potts, K. Mokross, M. A. Lewis, A unifying framework for quantifying the nature of animal interactions. J.R Soc. Interface 11, 20140333 (2014). doi: 10.1098/rsif 2014.0333; pmid: 24829284

98. J. R. Potts, M. A. Lewis, How do animal territories form and change? Lessons from 20 years of mechanistic modelling. Proc. R. Soc. Lond. B Biol Sci. 281 (2014)

99. A. W. Bateman, M. A. Lewis, G. Gall, M. B. Manser, T. H. Clutton Brock. Territoriality and home range dynamics in meerkats, Suricata suricatta: A mechanistic modelling approach. J. Anim. Ecol. 84, 260271 (2015), doi: 10.1111/ 13652656.12267

100. M. Nagy, Z. Akos, D. Biro, T. Vicsek, Hierarchical group dynamics in pigeon flocks. Nature 464, 890893 (2010). do: 10.1038/nature08891; pmid: 20376149

101. M. Nagy et al., Context dependent hierarchies in pigeons. Proc. Natl. Acad. Sci. U.SA. 110, 1304913054 (2013). do: 10.1073/pnas.1305552110; pmid: 23878247

102. B. Pettit, A. Perna, D. Biro, D. J.T. Sumpter, Interaction rules underlying group decisions in homing pigeons. $\perp . R$. S $\propto$. Interface 10. 20130529 (2013). doi: 10.1098/rsif.2013.0529 pmid: 24068173

103. A. J. King et al., Selfish herd behaviour of sheep under threat. Curr. Biol. 22, R561 R562 (2012). doi: 10.1016/ j.cub 2012.05.008; pmid: 22835787
104. W. Jetz, K. G. Ashton, F. A. La Sorte, Phenotypic population divergence in terrestrial vertebrates at macro scales. Ecol. Lett 12, 11371146 (2009). doi: $101111 /$ /1461 0248.2009.01369.x; pmid: 19708969

105. D. I. Bolnick et al., Why intraspecific trait variation matters in community ecology. Trends Ecol. Evol. 26, 183192 (2011). doi: 10.1016/j.tree.2011.01.009; pmid: 21367482

106. B. Kranstauber et al., The Movebank data model for animal tracking. Environ. Model. Softw. 26, 834835 (2011). doi: $10.1016 /$ i.envsoft.201012.005

107. H. M. Pereira et al., Ecology. Essential biodiversity variables. Science 339, 277278 (2013). doi: 10.1126/science.1229931; pmid: 23329036

108. R.E. van Wiket al., Individually tracked geese follow peaks of temperature acceleration during spring migration. Oikos $\mathbf{1 2 1}$. 655664 (2012). doi: $10.1111 / \mathrm{j} .16000706 .2011 .20083 . x$

109. J. Shamoun Baranes, W. Bouten, C. Camphuysen, E. Baaii, Riding the tide: Intriguing observations of gulls resting at sea during breeding. Ibis 153,411 415 (2011). doi: 101111/ j.1474 $919 \times 2010.01096 x$

110. R. A. Grant, T. Halliday, Predicting the unpredictable: evidence of pre seismic anticipatory behaviour in the common toad. J. Zool. (Lond.) 281263271 (2010). doi: $10.1111 / 14697998.2010 .00700 . x$

11. M. Wikelski, U. Mueller, W. A. Heidrich, F. X. Kuemmeth, Disaster alert mediation using nature. (2014) (available at Patent priority EP20120167197 20120508. W02013167661)

112. N. E. Hussey et al, Aquatic animal telemetry across diverse scales: Discovery, applications and relevance. Science 348 1255642 (2015)

113. I. D. Couzin, Collective cognition in animal groups. Trends Cogn. Sci. 13, 3643 (2009). doi: 10.1016/itics.2008.10.002 pmid: 19058992

114. A Flack et al, MPIO White stork lifetime tracking data. Movebank Data Repository (2015). doi: 10.5441/001/ $178152 p 3 q$

115. R. Kays et al., Tracking animal location and activity with an automated radio telemetry system in a tropical rainforest. Comput. J. 54, 19311948 (2011).

116. T. Mueller, J. Lenz, T. Caprano, W. Fiedler, K. Bơhning Gaese, Large frugivorous birds facilitate functional connectivity of fragmented landscapes. J. Appl. Ecol. 51, 684692 (2014). do: $101111 / 1365266412247$

\section{ACKNOWLEDGMENTS}

B. Carlson, J. Hody, K. Mertes, and J. Perrine read a previous draft and offered constructive comments. S. Dodge helped with data for Fig. 5. Work on this study was supported by NASA Biodiversity Grant NNX11AP72G and NSF grants EF 1232442, DBI 0756920, DBI 0960550, DBI 1262600, BCS 1440755, DEB 1026764, DEB 1441737 and IOS 1250895. The range map for Fig. 1 was provided by Birdlife International and NatureServe and the photograph by M. Kaatz. $M$. Berger and R. Weinzierl made the animation. Photographs are courtesy of D. Brown, R. Henrik. C. Markham. M. McGaw, K. Thorup, and N. Weber. 